\title{
012 PP 'THE OUTSIDERS FROM WITHIN' - COPING AND ADAPTIVE STRATEGIES FOR SYSTEMS RESILIENCE IN THE PROCESS OF IMPLEMENTING POLITICAL DEVOLUTION WITHIN THE HEALTH SECTOR IN KENYA
}

B Tsofa, ${ }^{1 *}$ S Molyneux, ${ }^{1,2}$ T Malingi, ${ }^{3}$ E Barasa ${ }^{1} .{ }^{1}$ KEMRI Wellcome Trust Research Programme, KEMRI Centre for Geographic Medicine Research Coast, Kenya; ${ }^{2}$ Centre for Tropical Medicine and Global Health, Nuffield Department of Medicine, University of Oxford, UK; ${ }^{3}$ County Department of Health, Kilifi County Government, Kenya

10.1136/bmjopen-2017-016492.30

Introduction Recent literature has underscored the value of health policy and systems research (HPSR) for systems strengthening. This discourse has highlighted the potential of HPSR as an intervention in itself, and the important role that researcherpolicy maker collaborations can have as conduits for real-time research translation.

Methods We set-up a health systems governance learning site in one of the 47 Kenyan counties, Kilifi, to analyse the implications of devolution on the health sector. This entailed being embedded in the contexts in which we carry out our research (county health departments, hospitals, primary health care facilities), and collaboratively working with health system actors at different levels to "learn" the system from within; to identify problems, formulate research questions and propose and document solutions.

Results Pre-devolution results highlighted the autonomy that hospital managers had over the management of user fees, and the central role these fees played in addressing critical day-to-day recurrent needs at county hospitals. Under devolution, all revenues collected at the county level had to be pooled into one county revenue account, removing the autonomy that hospital managers had over user fees. This presented a challenge to hospitals, who were now unable to pay their routine bills, procure emergency supplies and other recurrent needs. We shared these observations to a broader stakeholder audience, which triggered policy dialogue and ultimately the development of county legislation to reinstate the autonomy that hospitals had over user fee collections.

Conclusions This example highlights how the relationships established between researchers and policy maker can over time lead to acting together in real-time to address practical health system challenges. 